\title{
Utilization of gastroprotective strategies for nonsteroidal anti-inflammatory drug-induced gastrointestinal events in a major teaching hospital
}

This article was published in the following Dove Press journal:

Therapeutics and Clinical Risk Management

10 November 2016

Number of times this article has been viewed

\author{
Hooi Leng Lee' \\ Siew Siang Chua' \\ Sanjiv Mahadeva ${ }^{2}$ \\ 'Department of Pharmacy, \\ ${ }^{2}$ Department of Medicine, Faculty of \\ Medicine, University of Malaya, Kuala \\ Lumpur, Malaysia
}

Background and purpose: Clinical guidelines recommend the prescribing of gastroprotective strategies in nonsteroidal anti-inflammatory drug (NSAID) users with risk factors for gastrointestinal (GI) ulcer or ulcer complications. However, these guidelines are not often translated into clinical practice. Therefore, the aim of this study was to investigate the utilization of gastroprotective strategies for NSAID-induced upper GI events in at-risk users in a major teaching hospital.

Patients and methods: A cross-sectional, observational, pharmacy-based study was conducted in a major Asian institution with both primary and secondary health care services. This study involved the screening of prescriptions for regular NSAIDs, and patients who met the inclusion criteria were recruited and interviewed using a questionnaire.

Results: Of the 409 participants recruited, $83.1 \%$ had at least one GI risk factor, of whom $70.3 \%$ did not receive appropriate gastroprotection. The most common GI risk factor was the use of high-dose NSAIDs (69.2\%), followed by participants aged 65 years and older $(22 \%)$ and concomitant use of low-dose aspirin (11.7\%). Appropriate gastroprotective strategies utilized consisted of the use of a cyclooxygenase (COX)-2 inhibitor alone or a nonselective NSAID plus a proton pump inhibitor (PPI) in the moderate-risk group and a COX-2 inhibitor plus a PPI in the high-risk group. Gastroprotective strategies were underutilized in $67.1 \%$ of at-risk participants and overutilized in $59.4 \%$ of those without risk factors. Co-prescription of a histamine-2 receptor antagonist at lower-than-recommended doses constituted $59 \%$ of the inappropriate gastroprotective agents used. Logistic regression analysis revealed patients aged 65 years and older (odds ratio, $1.89 ; 95 \% \mathrm{CI}=1.15-3.09$ ) as a predictor for the prescribing of gastroprotection by the clinicians.

Conclusion: Approximately 70\% of at-risk NSAID users, mainly on high-dose NSAIDs, were not prescribed appropriate gastroprotective strategies. Further measures are warranted to improve the safe prescribing of regular NSAIDs.

Keywords: NSAID, COX-2 inhibitor, risk factor, proton pump inhibitor

\section{Introduction}

Nonsteroidal anti-inflammatory drugs (NSAIDs) are the mainstay treatment for the alleviation of pain and inflammation that are both acute and chronic in nature. ${ }^{1,2}$ However, the usefulness of NSAIDs is often plagued by its adverse effects that may affect the renal, ${ }^{3}$ cardiovascular ${ }^{4,5}$ and gastrointestinal (GI) systems. ${ }^{6-9}$ NSAID-induced upper GI (UGI) effects are the most commonly reported, namely dyspepsia that affects $5 \%-50 \%$ of users, ${ }^{10,11}$ endoscopic ulcers $(5 \%-30 \%)^{2,12}$ and serious ulcer complications, such as perforation, obstruction and bleeding ( $1 \%-2 \%$ of chronic users), which often lead to hospitalization and even death. ${ }^{13}$
Correspondence: Siew Siang Chua Department of Pharmacy, Faculty of Medicine, University of Malaya, Jalan Pantai Baharu, 50603 Kuala Lumpur, Malaysia

Tel +60 193363223

Fax +60379674964

Email chuass@um.edu.my 
In addition to the four- to fivefold increased risk of developing serious UGI ulcer complications compared to nonusers, ${ }^{7,14}$ NSAID users are subjected to a further two- to tenfold risk, depending on the presence of GI risk factors in the individual. ${ }^{15}$ Definite GI risk factors recognized by most practice guidelines are as follows: a history of GI ulcer with/ without complication, advanced age, use of concomitant medications such as corticosteroids, anticoagulants and aspirin, and the use of high-dose NSAIDs. ${ }^{16}$ The MUCOSA trial found that the annual incidence of NSAID-induced GI complications increased from $0.8 \%$ in patients with no risk factor to $18 \%$ in those with four risk factors. ${ }^{17}$ As such, practice guidelines globally have recommended that NSAID users with at least one GI risk factor be prescribed gastroprotective strategies, namely 1) co-prescription of nonselective NSAID (nsNSAID) with a gastroprotective agent (GPA) such as misoprostol, a double-dose histamine-2 receptor antagonist (H2RA) and a proton pump inhibitor (PPI) and 2) use of a cyclooxygenase (COX)-2 selective inhibitor instead of an nsNSAID. ${ }^{18-21}$

Nevertheless, the problem of NSAID-induced UGI adverse effects is still not being managed successfully. A recent systematic review revealed that more than half of the NSAID users with risk factors did not receive appropriate gastroprotection, although the weighted mean GPA co-prescribing rate had improved slightly over the years. ${ }^{22}$

Thus far, the utilization of gastroprotective strategies in Malaysia is still not well documented, and yet the use of NSAIDs is expected to increase continually, especially among the elderly population. Anti-inflammatory and antirheumatic medications were ranked as the seventh most commonly used drugs by therapeutic group in 2008 (11.2247 defined daily dose $/ 1,000$ population per day), with an estimated $1.12 \%$ of the Malaysian population utilizing them. ${ }^{23}$ Therefore, the aim of this study was to identify the risk factors for UGI events in NSAID users and to assess the appropriateness of gastroprotective strategies used in a major hospital in Malaysia.

\section{Patients and methods Study design and population}

A cross-sectional, observational study was conducted in a major Asian teaching hospital. Patients were recruited via convenience sampling of prescriptions with NSAIDs, from April 2013 to May 2015. Patients who filled their NSAID prescriptions at the outpatient pharmacy of the teaching hospital were approached to participate in the study. Six types of NSAIDs were available at the outpatient pharmacy: diclofenac sodium (Na) (Zolterol sustained release $[\mathrm{SR}]^{\circledR}, \mathrm{CCM}$ Pharmaceuticals, Kuala Lumpur, Malaysia), meloxicam (Melartin ${ }^{\circledR}$, Ranbaxy, Gurgaon, India), indomethacin (Indocid ${ }^{\circledR}$, Merck
Sharp \& Dohme, Kenilworth, NJ, USA), mefenamic acid (Pontacid $^{\circledR}$, CCM Duopharma Biotech, Kuala Lumpur, Malaysia), celecoxib (Celebrex ${ }^{\circledR}$, Pfizer, New York, NY, USA) and etoricoxib (Arcoxia ${ }^{\circledR}$, Merck Sharp \& Dohme).

Patients aged 21 years and older, able to communicate in English, Malay or Chinese and were on at least one regular NSAID for a minimum of 2 weeks were included in this study. Patients who were prescribed an NSAID on an "asneeded" basis, prescribed only aspirin and no other NSAID, given the quantity of NSAID that was for $<2$ weeks, had serious comorbidities such as stroke and serious trauma, and had poor cognitive function were excluded from the study.

The required sample size was calculated based on a confidence level of $95 \%$, within $5 \%$ margin of error, for an infinite study population size, assuming that $50 \%$ of the study population was given appropriate gastroprotection. Using the formula by Daniel and Cross,${ }^{24}$ the sample size required was 384 . Therefore, at least 400 patients who met the inclusion criteria needed to be included in this study.

\section{Study outcome measures and data collection}

The outcome measures of this study were: 1) types and number of GI risk factors among the NSAID users and 2) types of gastroprotective strategies prescribed. The American College of Gastroenterology (ACG) guidelines for the prevention of NSAID-related ulcer complications ${ }^{20}$ were used as the reference. The use of any concomitant PPI or doubledose H2RA during the entire prescribed duration of NSAID therapy, or the use of COX-2 inhibitor alone, was considered as a gastroprotective strategy for NSAID-associated GI events. No misoprostol co-prescription was included in this study as it was not available in the hospital drug formulary.

The recommended doses of PPIs for gastroprotection were omeprazole (20 mg/day), pantoprazole ( $20 \mathrm{mg}$ /day) and esomeprazole ( $20 \mathrm{mg} /$ day). ${ }^{25}$ Double-dose H2RA was defined as a dose of $\geq 300 \mathrm{mg}$ of ranitidine twice daily. ${ }^{21}$ Inappropriate gastroprotective strategies referred to the use of GPAs that were not in accordance with the ACG recommendations, in terms of dosages or coverage of NSAID duration, including the use of antacid. ${ }^{25}$ On the contrary, the absence of gastroprotective strategy meant that no gastroprotective strategy, whether appropriate or inappropriate, was prescribed.

During the data collection period, a researcher was stationed at the outpatient pharmacy to screen prescriptions and identify potential participants who met the inclusion criteria. The researcher then approached the potential participant and explained the study to him/her using a "participant information sheet". If the potential participant agreed to 
participate in the study, he/she was requested to sign an informed consent form. The researcher then interviewed the participant using a structured questionnaire. The information obtained included the presence of the following GI risk factors: 1) history of GI ulcer with/without complications; 2) age $\geq 65$ years; 3 ) concomitant anticoagulant use; 4) concomitant corticosteroid use; 5) concomitant use of low-dose aspirin or other antiplatelets; 6) multiple NSAIDs use and 8 ) use of high-dose NSAID. ${ }^{20}$

High-dose NSAID was defined as any NSAID treatment prescribed at the maximum dose recommended for the symptomatic treatment of arthritic pain. ${ }^{25,26}$ This included diclofenac $\geq 150 \mathrm{mg} /$ day, meloxicam $\geq 15 \mathrm{mg} /$ day, indomethacin $\geq 150 \mathrm{mg} /$ day, celecoxib $\geq 400 \mathrm{mg} /$ day and etoricoxib $\geq 90 \mathrm{mg} /$ day. ${ }^{21,25-29}$ After the interview, the researcher checked the pharmacy information system and the participant's medical record to confirm and extract the data, such as current medications and history of prescribed NSAID use.

Information gathered on participants' medical history, history of prescribed NSAID and previous GI ulcers, as well as current medications and comorbidities were limited to that available in the medical records of the institution under study and also from the interviews. Therefore, this information might not be complete if participants sought treatment or were under follow-up in other clinics or hospitals.

This study was approved by the Medical Ethics Committee of University Malaya Medical Centre (reference number: 956.88). To ensure anonymity, no participant's name was indicated in the questionnaire. All participants provided written informed consent.

\section{Statistical analysis}

All data were entered and analyzed using the PASW Statistics for Windows, Version 18 (SPSS Inc., Chicago, IL, USA). Descriptive statistics were generated to describe all the variables. Continuous variables were analyzed for mean, standard deviation, median and interquartile range. Models of logistic regression were constructed to determine the risk factors for NSAID-induced UGI events which were associated with the prescribing of gastroprotective strategies. Backward stepwise (likelihood ratio) was selected as the method in this binary logistic regression. A $P$-value of $<0.05$ was considered statistically significant.

\section{Results}

During the study period, a total of 9,535 prescriptions with NSAIDs were screened, of which only 1,180 met the inclusion criteria. However, only 561 patients were available and were approached to participate in the study. A total of 413 patients agreed to participate; of whom four were subsequently excluded. The number and reasons for the exclusion of NSAID prescriptions as well as patients are shown in Figure 1. Therefore, 409 participants were included in the final analysis.

\section{Characteristics of participants and NSAIDs prescribed}

The characteristics of participants and NSAIDs prescribed are summarized in Table 1. The age of participants ranged

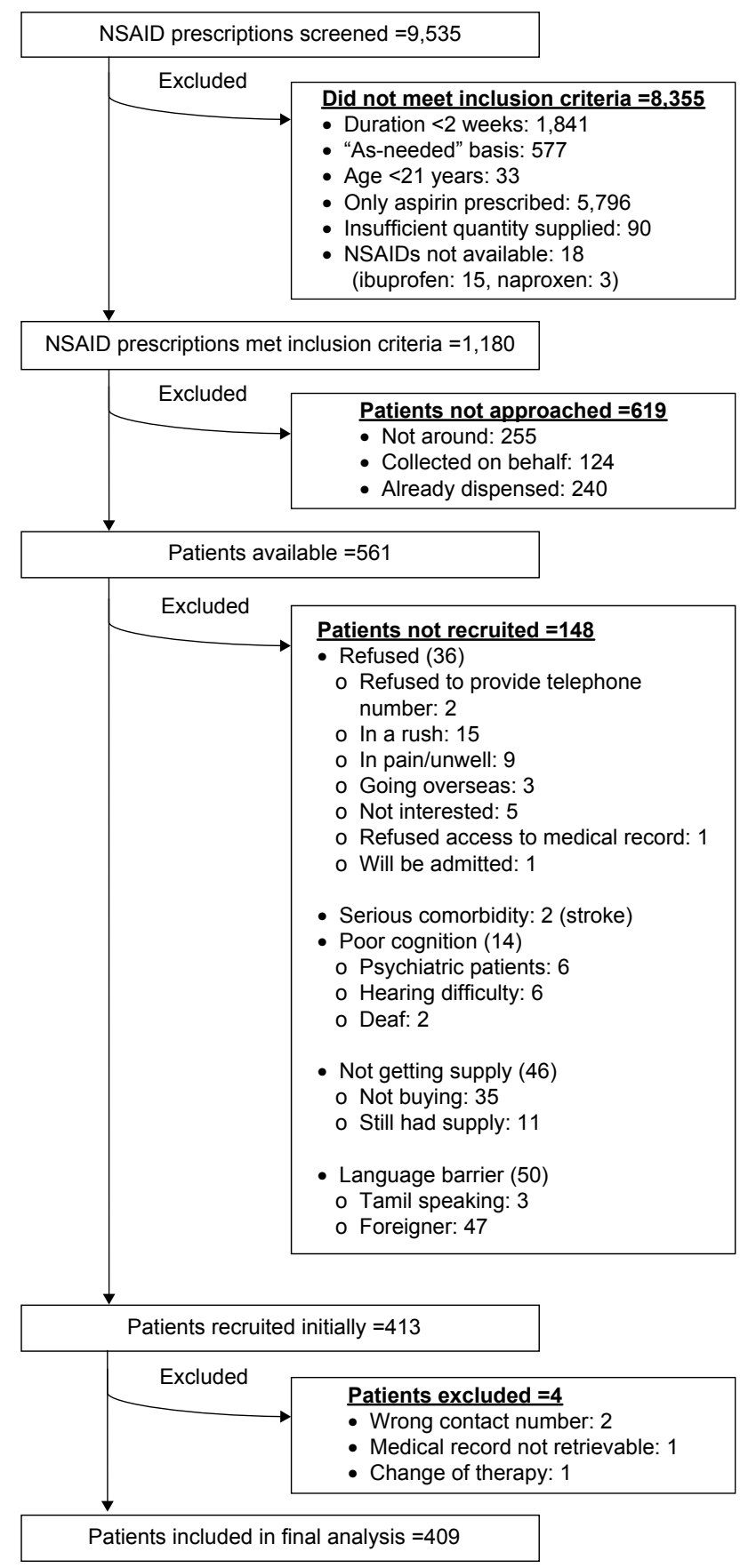

Figure I Exclusion details of NSAID prescriptions and patients. Abbreviation: NSAID, nonsteroidal anti-inflammatory drug. 
Table I Characteristics of participants and NSAIDs prescribed ( $\mathrm{N}=409)$

\begin{tabular}{|c|c|}
\hline Characteristics & Frequency (\%) \\
\hline Mean age (SD) (years) & $52.3(14.6)$ \\
\hline Median age (IQR) (years) & $53(2 I)$ \\
\hline \multicolumn{2}{|l|}{ Gender } \\
\hline Female & $248(60.6)$ \\
\hline Male & $161(39.4)$ \\
\hline \multicolumn{2}{|l|}{ Ethnic groups } \\
\hline Malay & $185(45.2)$ \\
\hline Chinese & $93(22.7)$ \\
\hline Indian & $124(30.3)$ \\
\hline Others & $7(1.8)$ \\
\hline \multicolumn{2}{|l|}{ Types of NSAIDs } \\
\hline Diclofenac $\mathrm{Na}$ & |81 (44.3) \\
\hline Meloxicam & $59(14.4)$ \\
\hline Indomethacin & $2(0.5)$ \\
\hline Celecoxib & $140(34.2)$ \\
\hline Etoricoxib & $23(5.6)$ \\
\hline Diclofenac $\mathrm{Na}+$ meloxicam & $\mathrm{I}(0.2)$ \\
\hline Diclofenac $\mathrm{Na}+$ indomethacin & $\mathrm{I}(0.2)$ \\
\hline Diclofenac $\mathrm{Na}+$ celecoxib & $2(0.5)$ \\
\hline \multicolumn{2}{|l|}{ Duration of therapy } \\
\hline 2 weeks & $273(66.7)$ \\
\hline$>2$ weeks to $\leq 8$ weeks & $119(29.1)$ \\
\hline$>8$ weeks to $\leq 24$ weeks & $17(4.2)$ \\
\hline \multicolumn{2}{|l|}{ Indications } \\
\hline Musculoskeletal disorders & $198(48.4)$ \\
\hline Osteoarthritis & $57(13.9)$ \\
\hline Vertebral degenerative diseases & $39(9.5)$ \\
\hline Rheumatoid arthritis & $13(3.2)$ \\
\hline Nerve-related disorders & $9(2.2)$ \\
\hline Ankylosing spondylitis & $\mathrm{I}(0.2)$ \\
\hline Others & $27(6.6)$ \\
\hline Not specified & $65(15.9)$ \\
\hline \multicolumn{2}{|l|}{ Sources (clinics by disciplines) } \\
\hline Primary care & $164(40.1)$ \\
\hline Surgical & $129(31.5)$ \\
\hline Medical & $85(20.8)$ \\
\hline Not specified & $31(7.6)$ \\
\hline
\end{tabular}

Abbreviations: IQR, interquartile range; $\mathrm{Na}$, sodium; NSAID, nonsteroidal antiinflammatory drug; SD, standard deviation.

from 21 to 83 years. Of the 409 participants, 90 were in the age group of 65 years and older, which was one of the risk factors for NSAID-induced GI events. Participants treated with COX-2 inhibitors were significantly older than those treated with nsNSAIDs; median age was 56 versus 52 years (Mann-Whitney $U$-test: $Z=-3.282, P=0.001$ ).

\section{Gl risk factors and the utilization of gastroprotective strategies}

Of the 409 participants, $340(83.1 \%)$ had at least one GI risk factor. Among these at-risk participants, 178 (52.4\%) were not prescribed any gastroprotective strategies at all. The number of participants with each of the seven GI risk factors and the number of GI risk factors are shown in Table 2. The absence of gastroprotective strategy in at-risk participants for each of the risk factors is also presented in Table 2. The risk factor with the most number of participants was the use of high-dose NSAIDs (69.2\%), followed by the age of participant $\geq 65$ years $(22 \%)$ and concomitant use of low-dose aspirin (11.7\%). Of the 283 participants who were given high-dose NSAIDs, $62.5 \%$ were prescribed diclofenac sodium SR $75 \mathrm{mg}$ twice daily, but a majority of these high-dose diclofenac users $(96.6 \%)$ did not receive appropriate gastroprotective strategies. Based on the ACG GI risk stratification and recommendations for the prevention of NSAID-related ulcer complications, the extent of inappropriate gastroprotective strategies under each category of GI risk is given in Table 3 .

Table 4 demonstrates the types of appropriate and inappropriate gastroprotective strategies used in accordance with the ACG recommendations. Inappropriate gastroprotection among the 409 participants consisted of the absence (43.5\%), underutilization (12.2\%) and overutilization (12.7\%) of gastroprotective strategies. However, among the 340 at-risk participants, 239 (70.3\%) did not receive appropriate gastroprotective strategies. In addition, gastroprotective strategies were underutilized in $67.1 \%$ of at-risk participants and overutilized in $59.4 \%$ of those without risk factors.

For participants with moderate GI risk, all the appropriately co-prescribed GPAs were omeprazole. Of the nine participants on omeprazole, three were given the standard dose for gastroprotection $(20 \mathrm{mg} /$ day $)$ and the other six at high dose (40 mg/day). Although high-dose omeprazole may not be necessary for gastroprotection, the six cases were deemed appropriate as the participants were found to have either a history of or underlying GI problems, such as dyspepsia and gastritis. Among the prescriptions with a GPA, three cases had the duration of omeprazole longer than the NSAID therapy. In one of these three cases, the longer PPI duration did not have any apparent GI reason, whereas in the other two cases the participants had underlying gastritis problems.

One of the two high GI risk participants with appropriate gastroprotection was given high-dose omeprazole (40 $\mathrm{mg} /$ day), whereas the other was prescribed high-dose pantoprazole (40 mg/day). Similarly, high PPI doses were acceptable in these cases as these participants had symptoms of dyspepsia and one of them also had a history of peptic ulcer disease. The duration of both the PPIs corresponded to that of the NSAIDs.

Inappropriate gastroprotective strategies prescribed included mainly the use of lower-dose H2RAs (59\%; 23/39 
Table 2 Participants with the types and number of risk factors for $\mathrm{Gl}$ events $(\mathrm{N}=409)$

\begin{tabular}{|c|c|c|}
\hline GI risk factors & $\begin{array}{l}\text { Number of } \\
\text { participants, } n(\%)\end{array}$ & $\begin{array}{l}\text { Number of at-risk participants } \\
\text { without gastroprotective strategy }\end{array}$ \\
\hline \multicolumn{3}{|l|}{ Types of risk factors } \\
\hline \multicolumn{3}{|l|}{ History of previous Gl ulcer } \\
\hline Complicated & $\mathrm{I}(0.2)$ & I \\
\hline Uncomplicated & $9(2.2)$ & 2 \\
\hline Age $\geq 65$ years & $90(22)$ & 33 \\
\hline Concomitant use of anticoagulants & $2(0.5)$ & 1 \\
\hline Concomitant use of corticosteroids & $17(4.2)$ & 3 \\
\hline \multicolumn{3}{|l|}{ Concomitant use of antiplatelets } \\
\hline Low-dose aspirin & $48(11.7)$ & 22 \\
\hline Other antiplatelets (eg, clopidogrel, ticlopidine) & $17(4.2)$ & 7 \\
\hline Multiple NSAIDs use & $4(1)$ & 4 \\
\hline Use of high-dose NSAID ${ }^{a}$ & $283(69.2)$ & 165 \\
\hline \multicolumn{3}{|l|}{ Number of risk factors } \\
\hline 0 & $69(16.9)$ & 28 \\
\hline 1 & $24 \mid(58.9)$ & 134 \\
\hline 2 & $74(18.1)$ & 32 \\
\hline 3 & $24(5.9)$ & 11 \\
\hline 4 & $\mathrm{I}(0.2)$ & 1 \\
\hline
\end{tabular}

Notes: aHigh-dose NSAID was defined as any NSAID treatment prescribed at the maximum dose recommended for the symptomatic treatment of arthritic pain. ${ }^{25,26}$ This included diclofenac $\geq 150 \mathrm{mg} /$ day, meloxicam $\geq 15 \mathrm{mg} /$ day, indomethacin $\geq 150 \mathrm{mg} /$ day, celecoxib $\geq 400 \mathrm{mg} /$ day and etoricoxib $\geq 90 \mathrm{mg} /$ day. ${ }^{21,25-29}$

Abbreviations: GI, gastrointestinal; NSAID, nonsteroidal anti-inflammatory drug.

Table 3 Summary of gastroprotective strategies prescribed

\begin{tabular}{|c|c|c|c|c|}
\hline \multirow[t]{2}{*}{ Particulars } & \multicolumn{4}{|l|}{ GI risk stratification } \\
\hline & Low & Moderate & High & Very high \\
\hline \multirow[t]{9}{*}{ Criteria* } & No risk factors & $\begin{array}{l}\text { Previous history } \\
\text { of uncomplicated ulcer }\end{array}$ & $\begin{array}{l}\text { Previous history of } \\
\text { complicated ulcer }\end{array}$ & $\begin{array}{l}\text { History of a recent } \\
\text { complicated ulcer }\end{array}$ \\
\hline & & Age $\geq 65$ years & $\begin{array}{l}\text { Presence of more than two } \\
\text { risk factors }\end{array}$ & \\
\hline & & Concomitant anticoagulant use & $\begin{array}{l}\text { Previous history of uncomplicated } \\
\text { ulcer }+ \text { concomitant use of } \\
\text { anticoagulant, corticosteroid, low- } \\
\text { dose aspirin or other antiplatelet }\end{array}$ & \\
\hline & & Concomitant corticosteroid use & & \\
\hline & & Concomitant low-dose aspirin & & \\
\hline & & or other antiplatelet use & & \\
\hline & & Multiple NSAIDs use & & \\
\hline & & High-dose NSAID & & \\
\hline & & $\begin{array}{l}\text { Presence of one to two } \\
\text { risk factors }\end{array}$ & & \\
\hline $\begin{array}{l}\text { Recommended } \\
\text { strategies* }\end{array}$ & $\begin{array}{l}\text { nsNSAID alone (the least } \\
\text { ulcerogenic nsNSAID at } \\
\text { the lowest effective dose) }\end{array}$ & $\begin{array}{l}\text { nsNSAID + PPI/misoprostol or } \\
\text { COX-2 inhibitor alone }\end{array}$ & $\begin{array}{l}\text { Avoid NSAID if possible } \\
\text { or COX-2 inhibitor + PPI/ } \\
\text { misoprostol }\end{array}$ & $\begin{array}{l}\text { Avoid NSAID if possible } \\
\text { or COX-2 inhibitor + } \\
\mathrm{PPI} / \text { misoprostol }\end{array}$ \\
\hline $\begin{array}{l}\text { Percentage } \\
\text { appropriateness of } \\
\text { gastroprotective } \\
\text { strategies used }\end{array}$ & $28 / 69(40.6)$ & $99 / 314(31.5)$ & 2/26 (7.7) & $\begin{array}{l}\text { No participant } \\
\text { categorized as such }\end{array}$ \\
\hline $\begin{array}{l}\text { Percentage } \\
\text { inappropriateness } \\
\text { of gastroprotective } \\
\text { strategies used }\end{array}$ & $4 \mathrm{I} / 69(59.4)$ & $2|5 / 3| 4(68.5)$ & $24 / 26(92.3)$ & Not applicable \\
\hline
\end{tabular}

Note: *Based on the ACG. ${ }^{20}$

Abbreviations: ACG, American College of Gastroenterology; COX, cyclooxygenase; GI, gastrointestinal; nsNSAID, nonselective nonsteroidal anti-inflammatory drug; NSAID, nonsteroidal anti-inflammatory drug; PPI, proton pump inhibitor. 
Table 4 Appropriateness of gastroprotective strategies prescribed

\begin{tabular}{|c|c|c|}
\hline GI risk & Appropriate gastroprotective strategies, $\mathrm{n}(\%)$ & Inappropriate gastroprotective strategies, $\mathbf{n}(\%)$ \\
\hline \multirow[t]{12}{*}{ Low } & No gastroprotective strategies required: & “Overutilization" of gastroprotective strategies: 4I/69 (59.4) \\
\hline & nsNSAID alone: $28 / 69(40.6)$ & Standard-dose PPI: I (I.4) \\
\hline & & High-dose PPI: I (I.4) \\
\hline & & COX-2 inhibitor: $27(39.1)$ \\
\hline & & COX-2 inhibitor + standard-dose PPI: I (I.4) \\
\hline & & COX-2 inhibitor + standard-dose PPI, as-needed basis: I (I.4) \\
\hline & & COX-2 inhibitor + high-dose PPI: I (I.4) \\
\hline & & COX-2 inhibitor + high-dose PPI, shorter duration: I (I.4) \\
\hline & & Lower-dose H2RA: 4 (5.8) \\
\hline & & Standard-dose PPI + lower-dose H2RA, both as-needed basis: I (I.4) \\
\hline & & Standard-dose PPI + lower-dose H2RA + antacid, as-needed basis: I (I.4) \\
\hline & & COX-2 inhibitor + lower-dose H2RA: 2 (2.9) \\
\hline \multirow[t]{17}{*}{ Moderate } & $99 / 314(31.5)$ & "No" gastroprotective strategies: 166/314 (52.9) \\
\hline & Standard-dose PPI: 3 (I) & "Overutilization" of gastroprotective strategies: I|/3|4 (3.2) \\
\hline & High-dose PPla: 6 (I.9) & High-dose PPI: I (0.3) \\
\hline & COX-2 inhibitor: 90 (28.7) & COX-2 inhibitor + standard-dose PPI: 4 (I.3) \\
\hline & & COX-2 inhibitor + high-dose PPI: 6 (I.9) \\
\hline & & "Underutilization" of gastroprotective strategies: $38 / 3$ I4 (I2.I) \\
\hline & & Lower-dose H2RA: 8 (2.5) \\
\hline & & Antacid: 6 (I.9) \\
\hline & & Lower-dose H2RA + antacid: I (0.3) \\
\hline & & Standard-dose PPI, as needed basis: $2(0.6)$ \\
\hline & & Standard-dose PPI, shorter duration: I (0.3) \\
\hline & & Standard-dose PPI + antacid: I (0.3) \\
\hline & & COX-2 inhibitor + standard-dose PPI, as-needed basis: $2(0.6)$ \\
\hline & & COX-2 inhibitor + lower-dose H2RA: 14 (4.5) \\
\hline & & COX-2 inhibitor + antacid: I (0.3) \\
\hline & & COX-2 inhibitor + standard-dose PPI + lower-dose H2RA: I (0.3) \\
\hline & & COX-2 inhibitor + standard-dose PPI + antacid: I (0.3) \\
\hline \multirow[t]{6}{*}{ High } & $2 / 26(7.7)$ & “No" gastroprotective strategies: I2/26 (46.2) \\
\hline & COX-2 inhibitor + high-dose PPI ${ }^{a}$ & "Underutilization” of gastroprotective strategies: I2/26 (46.2) \\
\hline & & Standard-dose PPI: 2 (7.7) \\
\hline & & High-dose PPIb: I (3.8) \\
\hline & & COX-2 inhibitor: 8 (30.8) \\
\hline & & COX-2 inhibitor + lower-dose H2RA: I (3.8) \\
\hline
\end{tabular}

Notes: aParticipants with history of Gl comorbidities. ${ }^{\mathrm{b} P a r t i c i p a n t s ~ w i t h o u t ~ h i s t o r y ~ o f ~ G l ~ c o m o r b i d i t i e s . ~}$

Abbreviations: COX, cyclooxygenase; GI, gastrointestinal; H2RA, histamine-2 receptor antagonist; nsNSAID, nonselective nonsteroidal anti-inflammatory drug; PPI, proton pump inhibitor.

participants), co-prescribed either with an nsNSAID or a COX-2 inhibitor. A majority of the H2RAs used were ranitidine $150 \mathrm{mg}$ twice daily (87\%; 20/23 participants). This was followed by antacids, either magnesium trisilicate tablets or mixtures $(17.9 \%$ of the participants).

\section{Predictors for prescribing of gastroprotective strategies}

Binary logistic regression was performed on the following four categories of GI risk factors: 1) age $\geq 65$ years; 2) history of UGI ulcers with/without complication; 3) use of high-dose NSAID and 4) multiple NSAIDs and concomitant use of antiplatelets, anticoagulants and corticosteroids. Risk factors that were not significantly associated with the prescribing of gastroprotective strategies for NSAID-induced UGI events were eliminated in each step (Table 5). From the first to the final step 3, the same two significant risk factors, namely age group $\geq 65$ years and the use of high-dose NSAID, were maintained. The step 3 results showed that participants aged 65 years and older were 1.89 times more likely whereas those prescribed with high-dose NSAIDs were approximately three times less likely (odds ratio $[\mathrm{OR}]=0.36$ ) to be prescribed a gastroprotective strategy. 
Table 5 Binary logistic regression output on Gl risk factors associated with prescribing of gastroprotective strategies

\begin{tabular}{|c|c|c|c|}
\hline Steps and variables & Wald test & $P$-value & OR $(95 \% \mathrm{Cl})$ \\
\hline \multicolumn{4}{|l|}{ Step I analysis ${ }^{\mathrm{a}}$} \\
\hline Age $\geq 65$ years & 4.616 & $0.032^{b}$ & $1.75(1.05-2.93)$ \\
\hline $\begin{array}{l}\text { History of UGI ulcer with/ } \\
\text { without complications }\end{array}$ & 0.351 & 0.554 & $1.54(0.37-6.43)$ \\
\hline High-dose NSAID use & 19.330 & $<0.00 \mathrm{I}^{\mathrm{c}}$ & $0.37(0.24-0.57)$ \\
\hline $\begin{array}{l}\text { Multiple NSAIDs and } \\
\text { the concomitant use of } \\
\text { antiplatelets, anticoagulants } \\
\text { and corticosteroids }\end{array}$ & 0.860 & 0.354 & $1.28(0.76-2.16)$ \\
\hline \multicolumn{4}{|l|}{ Step 2 analysis ${ }^{\mathrm{a}}$} \\
\hline Age $\geq 65$ years & 5.237 & $0.022^{b}$ & $1.80(1.09-2.98)$ \\
\hline High-dose NSAID use & $19.58 \mid$ & $<0.00 \mathrm{I}^{\mathrm{c}}$ & $0.36(0.23-0.57)$ \\
\hline $\begin{array}{l}\text { Multiple NSAIDs and } \\
\text { the concomitant use of } \\
\text { antiplatelets, anticoagulants } \\
\text { and corticosteroids }\end{array}$ & 0.858 & 0.354 & $1.28(0.76-2.16)$ \\
\hline \multicolumn{4}{|l|}{ Step 3 analysis ${ }^{\mathrm{a}}$} \\
\hline Age $\geq 65$ years & 6.290 & $0.012^{b}$ & $1.89(1.15-3.09)$ \\
\hline High-dose NSAID use & 20.275 & $<0.001^{c}$ & $0.36(0.23-0.56)$ \\
\hline
\end{tabular}

Notes: ${ }^{a}$ Variables entered in the binary regression analysis were as follows: age $\geq 65$ years; history of UGI ulcer with/without complications; use of high-dose NSAID; multiple NSAIDs and concomitant use of antiplatelets, anticoagulants and corticosteroids. 'Statistically significant at $P<0.05$. 'Statistically significant at $P<0.01$.

Abbreviations: $\mathrm{Cl}$, confidence interval; NSAID, nonsteroidal anti-inflammatory drug; OR, odds ratio; UGI, upper gastrointestinal.

\section{Discussion}

Inappropriate utilization of gastroprotective strategies in NSAID users with GI risk factors in this study was $70.3 \%$. Even more critical was the number of at-risk NSAID users who did not receive any gastroprotective strategy (178 participants; $52.4 \%$ ). These users should not be denied appropriate gastroprotection and hence, subjected to unnecessary risk of GI complications since established clinical guidelines as well as cost-effective GPAs, such as generic PPIs, are currently easily available.

The high prevalence of inappropriate or absence of gastroprotection among NSAID users had also been reported by Moore et $\mathrm{al}^{22}$ in their systematic review. However, as highlighted by Rostom et al, ${ }^{21}$ direct comparisons of the magnitudes of prevalence should be avoided as all studies had different patient populations, GI risk factors consideration or guidelines used. Since this study used the ACG guidelines as the reference, the utilization of gastroprotective strategies was determined based on both the nature and number of GI risk factors present, ${ }^{20}$ and not separately as reported by most other studies. ${ }^{27,30-32}$ Furthermore, this study adopted the ACG stratification of NSAID users into low, moderate and high GI risk groups, each entailing different gastroprotective strategy approaches. Such stratification of GI risk was also not commonly adopted by the other studies mentioned. ${ }^{27,30-32}$ For instance, patients with a single risk factor of a previous history of complicated GI ulcer are deemed at high risk of developing NSAID-induced ulcer complication and hence, need to be prescribed a COX-2 inhibitor plus a PPI or misoprostol.

The frequent usage of high-dose diclofenac sodium $(150 \mathrm{mg} /$ day; the most common risk factor in the current study) is of particular concern as it is one of the most commonly prescribed NSAIDs in Malaysia. ${ }^{23,33}$ Of the 283 participants given high-dose NSAIDs in the current study, 62.5\% were prescribed diclofenac sodium SR $75 \mathrm{mg}$ twice daily, and a majority of these users $(96.6 \%)$ were not co-prescribed with appropriate gastroprotective strategies. This practice is in contrast to those in the European countries which recorded only $1.2 \%$ to $34.2 \%$ of high-dose NSAID users. ${ }^{25,27}$ This indicates that insufficient emphasis has been given to high-dose NSAIDs as a GI risk factor and hence, the gastroprotection rate was lower.

The second highest GI risk factor in this study was the age of the patient being $\geq 65$ years $(22 \%)$. Elderly population has been the focus of many NSAID studies as this age group often constituted the most common GI risk factor. ${ }^{27,34}$ Of the 90 elderly participants in the current study, 33 (36.6\%) did not received any gastroprotection. Gulmez et $\mathrm{al}^{34}$ noted the low co-prescribing rate of GPAs (36\%) in their study and attributed that to the use of the Beers criteria at that time.

The age of the patients $\geq 65$ years was found to be significantly associated with the prescribing of gastroprotective strategies which is similar to that of other studies..$^{27,35}$ In the current study, elderly patients were approximately two times more likely to be prescribed a gastroprotective strategy. This could be due to their higher susceptibility to medication side effects compared to the younger patients. Besides that, advanced age is also an easily identifiable risk factor. On the contrary, those given high-dose NSAIDs were approximately three times less likely to be prescribed a gastroprotective strategy. This is in contrast to studies by Abraham et $\mathrm{al}^{36}$ and Thiéfin and Schwalm, ${ }^{27}$ which reported ORs of 1.26 and 1.8, respectively. This risk factor is significant, using the binary regression analysis, probably due to its high prevalence in the current study. It is possible that most of the prescribers did not realize that the maximum recommended doses were considered as high dose, and hence they did not consider any gastroprotective strategy. Since high-dose NSAIDs had been associated with a relative risk of 7.0 for developing upper GI clinical events, ${ }^{21}$ measures should be taken to highlight this risk factor. 
The current study recorded a $12.7 \%$ rate of overutilization of gastroprotective strategies, which involved 52 participants. This rate is comparable to other studies ${ }^{27,37}$ and warrants attention from health care providers. As highlighted by Thiéfin and Schwalm, ${ }^{27}$ overutilization of gastroprotective strategies posed a major concern to public health due to the need to redirect available resources from the overtreated to undertreated patients. In addition, while almost all the duration of PPI therapies correlated with that of the NSAIDs, coverage with a PPI was more than required in eight cases while inadequate in another eight. Sturkenboom et $\mathrm{al}^{30}$ highlighted the extended use of GPAs following the discontinuation of NSAIDs, whereas other authors ${ }^{31,32}$ reported partial coverage (defined as $<80 \%$ ) of NSAID treatment days with GPAs.

None of the H2RAs prescribed as GPAs in this study were of the recommended double dose for the prevention of NSAID-induced GI ulcer. This indicates an urgent need to ensure that the use of these agents is optimized to avoid unnecessary wastage of resources and to avoid increasing the risk of GI complications. Previous studies ${ }^{30,37,38}$ had also highlighted this issue, in which $85 \%-96 \%$ of the co-prescribed H2RAs were of inadequate doses.

The limitations in the current study include an overestimation of gastroprotection. This was due to the assumption that any GPA or antacid treatment given in the same prescription as an NSAID was meant to be used as a gastroprotective strategy, without considering the other indications of these medications prior to NSAID treatment. Second, the findings from this large, single-center study may not be generalizable to other health care institutions. However, since the hospital's outpatient pharmacy serves both primary and secondary care clinics, this study may also be representative of the community settings.

\section{Conclusion}

This study confirmed the challenges in preventing GI complications induced by NSAIDs. Awareness of health care providers needs to be increased, and improvement initiatives should be implemented promptly to ensure at-risk NSAID users are not exposed to preventable GI adverse events. A checklist of the risk factors could be prepared to help the physicians identify patients who require gastroprotective strategies. The checklist could also be incorporated into electronic prescribing, where the physicians or the pharmacy staff will be alerted if there is any inappropriate utilization of NSAIDs or gastroprotective strategies. Coté et $\mathrm{al}^{39}$ reported that the odds of PPI-naive high-risk NSAID users receiving gastroprotection was 1.8 times more with computer alert alone, 1.6 with physician education alone and 2.9 with the combination of both methods $(P<0.0001)$. In addition, future studies should also consider the cardiovascular risk in NSAID users.

\section{Acknowledgments}

The authors would like to thank all participants and pharmacy staff of the outpatient pharmacy in the University Malaya Medical Centre, especially Mr Alias Bin Aris, Mr Law Kok Seng and Ms Cheryl Shajini Pereira, for their assistance and cooperation throughout this study. This study was fully funded by the Postgraduate Research Grant from the University of Malaya (PG017-2013A).

\section{Disclosure}

The authors report no conflicts of interest in this work.

\section{References}

1. Deeks JJ, Smith LA, Bradley MD. Efficacy, tolerability, and upper gastrointestinal safety of celecoxib for treatment of osteoarthritis and rheumatoid arthritis: systematic review of randomised controlled trials. BMJ. 2002;325(7365):619.

2. Vonkeman HE, van de Laar MA. Nonsteroidal anti-inflammatory drugs: adverse effects and their prevention. Semin Arthritis Rheum. 2010; 39(4):294-312

3. Rose BD, Post TW. Clinical Physiology of Acid-Base and Electrolyte Disorders. 5th ed. New York, NY: McGraw Hill; 2001.

4. Feenstra J, Heerdink ER, Grobbee DE, Stricker BH. Association of nonsteroidal anti-inflammatory drugs with first occurrence of heart failure and with relapsing heart failure: The Rotterdam Study. Arch Intern Med. 2002;162(3):265-270.

5. Vonkeman HE, Brouwers JR, van de Laar MA. Understanding the NSAID related risk of vascular events. BMJ. 2006;332:895-898.

6. Coxib and Traditional NSAID Trialists' (CNT) Collaboration; Bhala N, Emberson J, et al. Vascular and upper gastrointestinal effects of nonsteroidal anti-inflammatory drugs: meta-analyses of individual participant data from randomised trials. Lancet. 2013;382(9894):769-779.

7. Hernández-Diaz S, Garcia Rodriguez LA. Association between nonsteroidal anti-inflammatory drugs and upper gastrointestinal tract bleeding/perforation: an overview of epidemiologic studies published in the 1990s. Arch Intern Med. 2000;160(14):2093-2099.

8. Richy F, Bruyene O, Ethgen O, et al. Time dependent risk of gastrointestinal complications induced by non-steroidal anti-inflammatory drug use: a consensus statement using a meta-analytic approach. Ann Rheum Dis. 2004;63(7):759-766

9. Sostres C, Gargallo CJ, Lanas A. Nonsteroidal anti-inflammatory drugs and upper and lower gastrointestinal mucosal damage. Arthritis Res Ther. 2013;15(suppl 3):S3.

10. Brun J, Jones R. Nonsteroidal anti-inflammatory drug-associated dyspepsia: the scale of the problem. Am J Med. 2001;110(1A):13S.

11. MacDonald TM. Epidemiology and pharmacoeconomic implications of non-steroidal anti-inflammatory drug-associated gastrointestinal toxicity. Rheumatology. 2000;39(suppl 2):13-20.

12. Lanas A, Hunt R. Prevention of anti-inflammatory drug-induced gastrointestinal damage: benefits and risks of therapeutic strategies. Ann Med. 2006;38(6):415-428.

13. Singh G, Ramey DR, Morfeld D, Shi H, Hatoum HT, Fries JF. Gastrointestinal tract complications of nonsteroidal anti-inflammatory drug treatment in rheumatoid arthritis. A prospective observational cohort study. Arch Intern Med. 1996;156(14):1530-1536. 
14. Huang JQ, Sridhar S, Hunt RH. Role of Helicobacter pylori infection and non-steroidal anti-inflammatory drugs in peptic-ulcer disease: a meta-analysis. Lancet. 2002;359(9300):14-22.

15. Venerito M, Wex T, Malfertheiner P. Nonsteroidal anti-inflammatory drug-induced gastroduodenal bleeding: risk factors and prevention strategies. Pharmaceuticals. 2010;3:2225-2237.

16. Fujita T, Kutsumi H, Sanuki T, Hayakumo T, Azuma T. Adherence to the preventive strategies for nonsteroidal anti-inflammatory drug- or lowdose aspirin-induced gastrointestinal injuries. J Gastroenterol. 2013;48: 559-573.

17. Silverstein FE, Graham DY, Senior JR, et al. Misoprostol reduces serious gastrointestinal complications in patients with rheumatoid arthritis receiving nonsteroidal anti-inflammatory drugs. A randomized, double-blind, placebo-controlled trial. Ann Intern Med. 1995;123(4): 241-249.

18. Burmester G, Lanas A, Biasucci L, et al. The appropriate use of nonsteroidal anti-inflammatory drugs in rheumatic disease: opinions of a multidisciplinary European expert panel. Ann Rheum Dis. 2011;70(5): 818-822.

19. Chan FK, Abraham NS, Scheiman JM, Laine L; First International Working Party on Gastrointestinal and Cardiovascular Effects of Nonsteroidal Anti-inflammatory Drugs and Anti-platelet Agents. Management of patients on nonsteroidal anti-inflammatory drugs: a clinical practice recommendation from the First International Working Party on Gastrointestinal and Cardiovascular Effects of Nonsteroidal Anti-inflammatory Drugs and Anti-platelet Agents. Am J Gastroenterol. 2008;103(11): 2908-2918.

20. Lanza FL, Chan FK, Quigley EM; the practice parameters committee of the American College of Gastroenterology. Guidelines for prevention of NSAID-related ulcer complications. Am J Gastroenterol. 2009;104(3): 728-738.

21. Rostom A, Moayyedi P, Hunt R; for the Canadian Association of Gastroenterology Consensus Group. Canadian consensus guidelines on long-term nonsteroidal anti-inflammatory drug therapy and the need for gastroprotection: benefits versus risks. Aliment Pharmacol Ther. 2009;29(5): 481-496.

22. Moore RA, Derry S, Simon LS, Emery P. Nonsteroidal anti-inflammatory drugs, gastroprotection, and benefit-risk. Pain Pract. 2014;14(4): 378-395.

23. Lian LM, Kamarudin A, Siti Fauziah A, Nik Nor Aklima NO, Norazida AR, editors. Malaysian Statistics on Medicines 2008. Selangor: Pharmaceutical Services Division \& the Clinical Research Centre, Ministry of Health Malaysia; 2009.

24. Daniel WW, Cross CL. Biostatistics: A Foundation for Analysis in the Health Sciences. 10th ed. USA: John Wiley \& Sons; 2013.

25. Lanas A, Polo-Tomás M, Roncales P, Gonzalez MA, Zapardiel J. Prescription of and adherence to non-steroidal anti-inflammatory drugs and gastroprotective agents in at-risk gastrointestinal patients Am J Gastroenterol. 2012;107(5):707-714.
26. Lanas A, Tornero J, Zamorano JL. Assessment of gastrointestinal and cardiovascular risk in patients with osteoarthritis who require NSAIDs: the LOGICA study. Ann Rheum Dis. 2010;69(8):1453-1458.

27. Thiéfin G, Schwalm MS. Underutilization of gastroprotective drugs in patients receiving non-steroidal anti-inflammatory drugs. Dig Liver Dis. 2011;43(3):209-214.

28. BMJ Publishing Group Ltd and Royal Pharmaceutical Society. British National Formulary March 2015 - September 2015. 69th ed. London: BMJ Group and Pharmaceutical Press; 2015.

29. Drugs.com [database on the Internet]. FDA Product Information: Indomethacin. United States: Food and Drug Administration; 2015 [updated September 1, 2015; cited October 26, 2015]. Available from: http://www.drugs.com/pro/indomethacin.html. Accessed October 26, 2015.

30. Sturkenboom MC, Burke TA, Tangelder MJ, Dieleman JP, Walton S, Goldstein JL. Adherence to proton pump inhibitors or H2-receptor antagonists during the use of non-steroidal anti-inflammatory drugs. Aliment Pharmacol Ther. 2003;18(11-12):1137-1147.

31. van Soest EM, Valkhoff VE, Mazzaglia G, et al. Suboptimal gastroprotective coverage of NSAID use and the risk of upper gastrointestinal bleeding and ulcers: an observational study using three European databases. Gut. 2011;60(12):1650-1659.

32. Valkhoff VE, van Soest EM, Mazzaglia G, et al. Adherence to gastroprotection during cyclooxygenase 2 inhibitor treatment and the risk of upper gastrointestinal tract events. Arthritis Rheum. 2012;64(8):2792-2802.

33. Chua SS, Paraidathathu T. Utilisation of non-steroidal anti-inflammatory drugs (NSAIDs) through community pharmacies in Malaysia. Asia Pac J Public Health. 2005;17(2):117-123.

34. Gulmez SE, Droz-Perroteau C, Lassalle R, et al; CADEUS Study Group. Are traditional NSAIDs prescribed appropriately among French elderly with osteoarthritis? Results from the CADEUS cohort. Eur J Clin Pharmacol. 2011;67(8):833-838.

35. Laine L, Connorst L, Griffin MR, Curtis SP, Kaur A, Cannon CP. Prescription rates of protective co-therapy for NSAID users at high GI risk and results of attempts to improve adherence to guidelines. Aliment Pharmacol Ther. 2009;30(7):767-774.

36. Abraham NS, El-Serag HB, Johnson ML, et al. National adherence to evidence-based guidelines for the prescription of nonsteroidal antiinflammatory drugs. Gastroenterol. 2005;129:1171-1178.

37. Valkhoff VE, van Soest EM, Sturkenboom MC, Kuipers EJ. Timetrends in gastroprotection with nonsteroidal anti-inflammatory drugs (NSAIDs). Aliment Pharmacol Ther. 2010;31(11):1218-1228.

38. van Soest EM, Sturkenboom MC, Dieleman JP, Verhamme KM, Siersema PD, Kuipers EJ. Adherence to gastroprotection and the risk of NSAID-related upper gastrointestinal ulcers and haemorrhage. Aliment Pharmacol Ther. 2007;26(2):265-275.

39. Coté GA, Rice JP, Bulsiewicz W, et al. Use of physician education and computer alert to improve targeted use of gastroprotection among NSAID users. Am J Gastroenterol. 2008;103(5):1097-1103.
Therapeutics and Clinical Risk Management

\section{Publish your work in this journal}

Therapeutics and Clinical Risk Management is an international, peerreviewed journal of clinical therapeutics and risk management, focusing on concise rapid reporting of clinical studies in all therapeutic areas outcomes, safety, and programs for the effective, safe, and sustained use of medicines. This journal is indexed on PubMed Central, CAS,

\section{Dovepress}

EMBase, Scopus and the Elsevier Bibliographic databases. The manuscript management system is completely online and includes a very quick and fair peer-review system, which is all easy to use. Visit http://www.dovepress.com/testimonials.php to read real quotes from published authors. 